\title{
From sexualized torture and gender-based torture to genderized torture: The urgent need for a conceptual evolution
}

\author{
Pau Pérez-Sales*, Maggie Zraly**
}

Classical perspectives on sexualized torture are being increasingly challenged by contemporary debates informed by emerging claims (Mendez, 2016; Sáez, 2016; Sifris, 2014). Gender-based analysis based on feminist and other theoretical approaches is needed to adequately address these. Arriving at a general framework for the reconceptualization of torture, and progressively widening the analytical scope of gender and torture, are priorities. Gender analyses of torture needs to encompass a broader range of phenomena, from rape and attacks on sexual integrity to any suffering inflicted on human beings that is intricately intertwined with gender (Jakobsen, 2014), including and not limited to discrimination against LGTBI persons, ${ }^{1}$ genital mutilation, and the restriction of any of the broad range of issues under the frame of reproductive freedom, such as abortion and involuntary sterilization. ${ }^{2}$

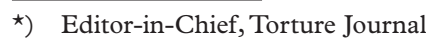

${ }^{\star}$ ) Associated Guest Editor for the Torture Journal Special Section on Sexual, Gender-Based and Genderized torture (Volume 28, No. 3, 2018)

1 Lesbian, gay, bisexual, transgender and intersex persons. The acronym 'LGBTI' encompasses a wide range of identities that share an experience of discrimination due to their sexual orientation and/or gender identity.

2 Here, gender analysis is conceived of as inclusive of gender mainstreaming as acknowledged by the $\mathrm{UN}(\mathrm{A} / 52 / 3)$ and seeks to go further by incorpo-
The push for a gender transformative rethinking of conceptual and analytical approaches to torture is accompanied by the need to develop specific tools to detect and assess sexual and gender-based torture (including the necessity for a reconsideration of gender perspectives on the Istanbul Protocol), to incorporate a feminist perspective in the rehabilitation of victims. This requires specific treatment approaches as well as holistic survivor-centered rehabilitation models that include access to high quality and comprehensive services. Services that support stigma reduction are particularly important.

Our own desk review on all papers published in Torture Journal since 2006 until 2018 showed a clear gender analysis gap: only $32 \%$ of papers included the word 'gender' and $38 \%$ the word 'female' in any part of the text. In $84 \%$ of the cases, these mentions simply indexed the presentation of data disaggregated by sex. Only $4 \%$ of all the papers published in the Journal attempted a gender analysis. To help address this gap, the Journal circulated a call for papers on gender and torture that aligned with research priorities identified in our

rating consideration of how gender inequalities are extended and maintained by incidents and circumstances of torture. 
Delphi study (Pérez-Sales, Witcombe, \& Otero, 2017).

The response to this call has been encouraging. This issue features a collection of texts that highlight important aspects of sexualized and gender-based torture and provide reflections that contribute to framing the theoretical debate on the nature and scope of gender-based and genderized forms of torture. The Journal believes that even more research and reflection is necessary to adequately clarify and raise the terms of this debate and additional texts relevant to the topic are planned to appear in forthcoming issues. This current issue draws out key concepts that are important to making an impact, both on the debate and in practice.

\section{Some definitions}

Here, sexual torture or sexualized torture refers to any intentional form of sexualrelated verbal, emotional or physical acts performed with the purpose of producing physical or psychological suffering to the person. Drawing on Merry's (2011) notion of gender violence, gender-based torture is defined as torture whose meaning depends on the gender identities of the persons involved. ${ }^{3}$ In this regard there can be forms of torture against women, men, boys, or girls that are not forms of sexual torture but are gender-based. Expanding the concept to gendered torture or genderized torture emphasizes what is gendered about genderbased torture, such as gender's influence on the meaning and purpose of acts of torture, and torture's role in maintaining gender

3 We recognize the distinction between biological sex, gender identity and sexual orientation. We include all of these under the broad term of gender-based in recognition of how the widespread policing and enforcement of binary and heteronormative gender norms shape patterns of torture. hierarchies as well as its relation to the experience, embodiment and performance of gender (Bumiller, 2010; Jakobson 2014). ${ }^{4}$ Rape as an act of torture, a maximum form of aggression, is thus constituted by: an attack on the body whose limits are broken (sexual torture); an attack on the woman, man, or non-binary person in their gendered identity and possibly their sexual orientation (gender-based torture); and, a specific aim to demolish the human being by using multilevel (i.e. macro, meso, micro) gender-linked elements that make the person more vulnerable (genderized torture). All definitions include violence in the public or private domain when the State has not fulfilled its obligation to protect.

Governmental and non-governmental organizations have been criticised for using narrow legislative definitions of torture that do not necessarily apply the same nuanced gendered understandings of sexual and gender-based violence to the forms of torture that women and men are often subjected to, which risks resulting in a social silencing of sexual torture (Canning, 2016). ${ }^{5}$

$4 \quad$ The category of gender is intersected with other categories within hierarchies of power by which many women and members of other gender and sexual minorities suffer the combination of multiple forms of discrimination to configure social stratification (Nash, 2008). Intersectionality is the critical insight that gender, sexuality, race, class, ethnicity, nation, ability, age, and other elements of identity operate not as unitary, mutually exclusive entities, but rather as reciprocally constructing phenomena (Collins, 2015). Alinia (2013) provides a good example of this kind of application of intersectionality in her analysis of violence against women in the context of political conflict.

5 Canning (2016) uses the phrase 'sexually torturous violence' to refer sexual violence that is torturous in nature in relation to its degradative objectives and effects but does not fall under the 
The terms we have put forward therefore help to amplify and advance definitions of sexual violence and gender-based violence routinely used by global mental health and humanitarian actors (IASC, 2015; UN, 1993; WHO, 2018) and provide foundational conceptual grounding for analysis and action in the specific domain of torture.

\section{Lack of data}

In Goodman \& Bandeira's (2014) literature review on gender and torture, they identify a dearth of research, particularly around gender difference on three topics: 1) susceptibility or vulnerability of women to torture victimization; 2) the prevalence and impact of sexual torture and violence by gender; 3) the susceptibility or vulnerability to developing or reporting psychiatric illnesses following torture, disaggregated by gender, and relatedly, coping strategies after torture. They also challenge the notion that sexual torture is more prevalent among women, citing the fact that there has not yet been enough documentation of the extent of torture among men as well as the glaring lack of data regarding sexual torture (in its wider concept, not limited to rape) among men (see also Sivakumaran (2007) for a review). Furthermore, they put forth the view that the paucity of data on gender and torture precludes any firm conclusion regarding an association between sexual torture and psychiatric disorders, however, they note some anecdotal data that suggests that men who experienced sexual torture in the form of rape may have increased rates of psychiatric

UN Convention's definition in relation to either state accountability or obtaining information. Under the definitions put forth above, sexual tortuous violence would be encompassed under sexual torture or sexualized torture. disorder (Peel, 2004). Their Delphi study of 18 worldwide experts shows a richness of results emphasizing that each sexual torture survivor case should be seen as unique and that generalizations were dangerous.

\section{Understanding gender oppression}

Sexual and gender-based torture can be fully understood only in relation to the sociocultural systems and contexts that give it meaning (see Scheper-Hughes \& Bourgois, 2004). It is closely linked to "the social cultural imaginaries of order and disorder; ... far from being an interruption of the ordinary, is folded into the ordinary" (Das, 2008, p. 283). Beyond the institutional spaces of secret prisons, detention centers, camps, and raids, the palpable effects of sexualized and genderized torture can be studied in ordinary community, family, and personal life, particularly in relation to oppression.

Oppression $^{6}$ can be defined as an enclosing structure that harms members of a social group while members of other privileged corresponding social groups benefit from the harm suffered by those oppressed. In her classical text, Frye (1983) has compared oppression as the situation of a bird in a cage:

"The living of one's life is confined and shaped by forces and barriers which are not accidental or occasional and hence avoidable, but are systematically related to each other (...). It is the experience of being caged in: All avenues, in every direction, are blocked or booby trapped."

6 Coercion is defined as forcing someone to do something against his or her will, to compel an act against one's will (Pérez-Sales, 2017). There is awareness of the pressure. In Opression this is not necessarily so, and the oppressed person may not be aware of their situation. 
At the intersection of oppression and gender, patriarchy appears as a system of social structures and practices, observed in social, political, and economic spheres, in which men dominate, oppress, and exploit women (Walby, 1990). Those who do not conform to norms of masculinity and femininity or heteronormative patterns of gender identity and sexual orientation face rejection and discrimination.

Taking an ecological approach to oppression and patriarchy with a focus on women, we can parse the social world into multiple layers of oppression that affect women in most countries and cultures (East and West) at the macro, meso, and micro levels. Although some examples of this are concrete, delineating between where these levels start and end and understanding how they interact, conflict and intermesh is both theoretically and empirically challenging. Nonetheless, the following is frequently observed.

- The State restricts full citizenship for women.

- The over-whelming majority of powerful economic and social positions in hierarchies are occupied by men. The majority of politicians are men, who rule the State, consciously or unconsciously, according to their own patriarchal preconceptions. Especially relevant is that the coercive force of the military and the police is mostly, if not entirely, controlled by men.

- Kin rules, in places where ethnicity and kinship determine social structure and hierarchy, prescribe submissive roles and relationships for women and exclude or punish dissidents.

- Family roles restrict women's differential possibilities of power, personal development, and exercise of free will and control over one's life. In its extreme form, men control women via family systems through conceptions of ownership, whereby a woman, like other possessions, is seen as an extension of a man.

- In many cultures and religions, family and social symbolism links collective honor to women's purity, virginity, chastity, and loyalty to male members of their group, and operates as a system of control, involving monitoring and physical or psychological punishment in the name of honor. ${ }^{7}$ Female genital mutilation, virginity examinations and so-called honor killings are part of this system. A variant of these dynamics of control play out through the appellation to family and social moral codes or rules for decision-making regarding which types of misbehaviour deserve which types of punishment, with different rules for men and women. The entire social and political system (including institutions such as school, media, and the judiciary among others) reinforces these oppressive dynamics.

- Finally, as some authors from the Global South point out, cultural discrimination by men and women from Western countries casts women from African or Middle Eastern countries as passive victims of all of the above (Adichie, 2014; Akul, 2017).

This patriarchal system of oppression is fluid and operates in a dialogical and intricate way that makes intervention complex. Intervention against local forms

Purity-fueled forms of oppression may shape the experience and expression of gender difference among women in the Middle East in particular ways that non-Middle Eastern women may not experience at all. 
of genderized torture can mean intervening against the ways that privilege is maintained for a social group. Where women's honor is bound up with men's masculinity and identity (which can be a form of oppression for both women and men), challenging genderized torture may mean challenging an entire family, cultural, and social structure.

The idea of patriarchy also reveals the connective tissues "between large and small, subtle and blatant forms of racialized sexism, gendered misogyny, and masculinized privilege" (Enloe, 2017, pp. ix-x). It makes visible the linkages between the personal and the political. By drawing attention to inequalities across gender and sexuality, the lens of gender-based analysis encourages questioning of the social order and interrogation of inequalities that create the conditions for coercion and discrimination. This is important to our analysis because coercion and discrimination are central to any kind of torture.

If the aim of torture is to break the will of the person and demolish their identity, in sexualized and genderized torture, the torturer uses the system of rules and norms and the moral codes in a society linked to sexuality and gender to attack the individual. Accordingly, the analysis must take as point of departure the individual's convictions about gender and its connection with dignity and honor. While the implications may be immediately evident in cases such as Castro-Castro (IACHR, 2008) or Abu Ghraib (Fortin, 2008), nakedness or rape are not necessary conditions of sexualized or genderized torture: they are extreme forms of it. From this standpoint, forcing a Muslim woman to unveil in the presence of military men would be a form of genderized mistreatment. Accordingly, analyses of genderized torture are relevant to the situations of many persons across diverse cultures among whom honor and/or dignity are essential elements to structuring a sense of the self.

In genderized torture, the person is attacked through self-conscious emotions of humiliation, shame, and guilt. The severity of suffering and the long-lasting psychological damage have been repeatedly documented in literature (Koenig, 2013).

\section{The legal contours}

The definition of torture in the UN

Convention against Torture specifically includes discrimination as a purpose that distinguishes ill-treatment from torture. Gender discrimination, thus, under certain conditions, can fulfil the criteria for torture (Amnesty International, 2001; MadrigalBorloz, 2017; Mendez, 2016; Redress \& Amnesty International, 2011; Sáez, 2016). This is particularly pertinent to lesbian, gay, bisexual and transgender rights activists that are seen as threatening the social or 'natural' order and thus subjected to moral condemnation, exclusion and violence, including torture.

Moving beyond discrimination, the State often interferes with the private lives of women by deciding on issues like abortion or sexual practices, particularly in Africa, East Asia and South America, and there is a debate on whether these practices could actually amount to torture (Mendez, 2016; Sifris, 2014; SRT, 2013).

In General Comment \#2, the Committee Against Torture established that: "Since the failure of the State to exercise due diligence to intervene to stop, sanction and provide remedies to victims of torture facilitates and enables non-State actors to commit acts impermissible under the Convention with impunity. The State's indifference or inaction provides a form of encouragement and/or de facto permission. The Committee 
has applied this principle to States parties' failure to prevent and protect victims from gender-based violence, such as rape, domestic violence, female genital mutilation and trafficking" (para 7 p. 2). Additionally, in December 2010, the United Nations General Assembly adopted the United Nations Rules for the Treatment of Women Prisoners and Non-custodial Measures for Women Offenders (Bangkok Rules) which addressed the specific needs of women in detention and the Subcommittee for the Prevention of Torture report on Prevention of torture and ill-treatment of women deprived of their liberty (SPT, 2016).

\section{Istanbul Protocol: Gender perspectives in the forensic documentation of torture}

The Istanbul Protocol (OHCHR, 2004) comes up short in its consideration of gender in relation to its categorization and list of torture methods, which includes "forced nudity, sexual violence on genitals and sexual abuse and rape ${ }^{8}$ (partial or complete penetration with genitals or objects)" (Para 145 p. 29). It also uses the word "sodomy" to refer to anal penetration

8 Interestingly, the International Rwanda Chamber Trial Rwanda (ICTR) in Prosecutor vs Akayesu, considered rape as torture and defined it as "a physical invasion of sexual nature, committed on a person under circumstances which are coercive" (Akayesu, case \# ICTR 96-4-T. Para 598, 688; Sept 2, 1998). The Chamber choose the word "invasion" rather than "penetration" because it expands the concept of rape and it is inclusive of violence against all gender options. The definition refers to the act of rape while at the same recognizing the diversity of embodied rape experience as well as the relentless embodied resistance among some survivors. It is the intend to use rape for such purposes as punishment, control, humiliation, degradation or discrimination that defines the crime. (i.e. para 99 p. 21 ; para 215 p. 41). Sexual torture, in the Istanbul Protocol, is related to "cultural taboos" (para 216 p. 41), a concept that does not link identity to gender aspects and to genderized torture. Using fear of losing virginity or threats of not being able to marry (both a common consequence of sexual torture in certain societies) are forms of genderized torture and go far beyond breaking cultural taboos. They can constitute a threat to the entire public life project of a woman. Genderized torture (and its associated psychological suffering and consequences) can only be documented and fully understood for forensic purposes in the overall context of the intersectional analysis of the structures of oppression and power that women disproportionately suffer, including but not limited to by partner, family, kinship, religion, ethnicity, society, and law.

The Sepur Zarco case in Guatemala, where a group of indigenous women denounced sexual slavery by the military more than 20 years after the events (UNAMG, 2011), is an example that demonstrates how the concept of sexual torture falls short when analyzing and documenting women's experience of torture in relation to gender (Impunity Watch, 2017). In the Sepur-Zarco case, there is a complex intersectional mixture of elements (i.e. poverty, ethnicity, negative family and community attitude, military power and fear, legal requirements) that must be taken into consideration to fully account for the subjective experience of torture and rape in a forensic assessment of torture.

The methods used to torture victims vary by gender. A genderized perspective goes beyond this fact. Given that torture targets basic physical and psychological human needs in order to break the will, a genderized perspective makes way for 
an exploration of the logic behind the gender difference in the treatment of torture victims. One obvious explanation is that most torturers are men and that the sadistic component of torture is enacted differently on men and women based on men's conceptions of what causes pain for male and female bodies. However, this reasoning is too simplistic and does not take a comprehensive enough view of torture (Genefke \& Vesti, 1998). For example, it is alleged that the process of efficaciously breaking a person requires some knowledge of the personal narrative of the victim as well as specific contextual expertise on culture and gender. From this perspective, gender difference in the use of torture methods is linked to the meaning of the person's identity in relation to culturally patterned gender roles.

Linking an analysis of gendered patterns of torture methods to a forensic genderized analysis of consequences is similarly illuminating. For many women, especially in societies where honor is relevant to selfconcept, rape constitutes an eclipse (see Cahill, 2001) or possible loss of inner self as linked to gendered ideals of purity and the socially imposed mandate to defend collective honor. For men among whom socially constructed ideas of what it means to be a man means being heterosexual, sexual torture is often associated with a fear of having become homosexual, in other words, of being degraded to not being a true man any more (Carpenter, 2006; Sivakumaran, 2007; Weishut, 2015). In certain contexts, for men for whom honor is dependent on the sexual purity of his wife, a man can likewise be degraded through his manhood by being subjected to the genderized torture of witnessing the rape of his wife. In each of these examples, sexual attacks to the body carry meaning that also attacks gender values and identities, including those that may be problematically bound up with gendered ideals that perpetuate discrimination and stigma. ${ }^{9}$ This is a dilemma. However, the International Forensic Expert Group has made it clear that state-sponsored homophobia, the policing and punishing of individuals on the basis of their sexual orientation, enacted through coercive anal examinations, "conducted almost exclusively on males in an effort to "prove homosexuality," is considered in cruel, inhuman, and degrading treatment that is also possibly torture (Alempijevic et al., 2016).

\section{Gender analysis in reporting torture}

This gender perspective is scarcely seen in reports documenting torture. An instructive example is the recent gender analysis of the eight Reports by the Independent International Commission of Inquiry on the Syrian Arab Republic ${ }^{10}$ (Bamber \& Hemfrey, 2014). The authors show that the reports' approach to taking a 'gender perspective' involves recording physical acts of torture and sexual violence along with information on the gender and age of the person attacked, but rarely refers to women outside of a purely sexual violence context. This very limited and unsatisfactory gender analysis approach reinforces the mainstream discourse that depicts women only as rape

9 As a case in point, Homero Flor Freire went to the Inter-American Court to challenge his separation from the Ecuadorean army on the basis of his perceived sexual orientation, not because he took issue with discrimination on the basis of sexuality but because he wanted to make it clear that he was not gay (Inter-American Court on Human Rights. 2016).

10 A Commission created by the UN Human Rights Council 
victims in war, thus compounding their invisibility in the global political economy of the war. A more acceptable gender perspective would include an analysis on where women's capacity to act with free agency is hindered by the protracted violence of war. It would not depict women as passive victims, but would include a vulnerability-capacity analysis by gender. ${ }^{11}$ A gender-approach would analyze the testimonies collected by the report including any action upon someone either because of, or to emphasize, their gender; this can include "anything from house raids where women's underwear is taken, the separation of men and women at checkpoints, to the sexual assault of a person's body, to the use of rape as a weapon in the conflict," (Bamber \& Hemfrey, 2014, p. 13) under the lens of gender. The only way this can be addressed is by interviewing both men and women with interview models that specifically addresses gender-related issues and a comprehensive analysis of the discourse, including, among other things, sexual related issues for both men and women. In this regard, Carpenter (2006) has specifically underlined the importance of collecting data on genderbased violence against men (including sexual violence, forced conscription, and sex-selective massacre), and the urgent need for such violence to be recognized as such, condemned, and addressed by civilian protection agencies and proponents of a 'human security' agenda in international relations. Men in their own right deserve

11 Creation of such an analysis might include an assessment of both vulnerability and coping capacity (for example see Nurius et al. 1992) across levels such as material, political/organizational, and motivational/attitudinal. protection against these abuses, particularly in those situations where civilian men are specifically vulnerable.

Practically speaking, consideration of the potential intersection of individuals' and groups' specific vulnerabilities, including gender vulnerabilities, can be used to improve the technical quality in the documentation of torture, including describing methods of discrimination, illtreatment and torture (an epidemiology of the oppressed), understanding pain, suffering and wider impacts, capturing nuances of intentionality and purpose, and re-thinking reparation policies.

\section{Gender and rehabilitation}

Because emotions associated with experiences of sexualized and genderized torture bridge individual bodies, social bodies and the body politic (Scheper-Hughes \& Lock, 1987), there is a need for a renewed investigation of the gendered mental health consequences of torture in ecological perspective. In genderized torture, the infliction of pain and suffering is linked to the meaning of the torture methods used in relation to gender identity and gendered hierarchies of power. When it comes to possibilities for healing and recovery, gender is also likely to matter in relation to making meaning of experiences. For example, a previous study with Rwandan women survivors of the extreme sexualized and genderized torture of genocide-rape found that making meaning through engaging in socially valued gendered roles and relationships, such as being a mother and joining associations of women genocide-rape survivors, could contribute to their capacity for resilience (Zraly \& Nyirazinyoye, 2010, Zraly, Rubin, \& Mukamana, 2013). This is important because it implies that gender analysis is needed to develop appropriate and effective support to promote mental health 
and psychosocial well-being among survivors of sexualized and gender-based torture.

The concept of embodied experience is key for deepening our understanding of gendered experience of sexualized and genderized torture, meaning, and mental health outcomes. From the perspective of the body (Scarry, 1985), torture and pain have been theorized as "world-destroying" (p. 29). But it is also argued that this destruction is coupled with a human response to find meaning in the experience (Good, 1994). Some feminist theories conceive of bodies as always sexed and situated, involved in motion where by interior experience are simultaneously shaping and shaped by exterior sociocultural contexts of meaning (Cahill, 2001; Braidotti 1994; Grosz, 1994; Irigaray, 1993). One implication of this idea for survivors of sexualized and genderized torture is that although their life trajectories may be limited by their individual internal psychological and emotional conditions as well as the external social, political, and economic conditions in which they find themselves, their pathways for recovery are indeterminate. Furthermore, while it is recognized that the State has a role in constructing affective experience and expression of torture, survivors' embodied experience is important to interpreting if these affects are normal or psychopathological (Jenkins, 1991; Jenkins \& Valiente, 1994).

Inspired by feminist analyses that direct our sensibilities toward domains of gender, embodiment, and meaning in recovery from sexual torture (Winkler, 1994), we seek to draw more attention to building knowledge about how and under which conditions some healing and recovery trajectories of survivors of sexual and genderized torture open while others close. Such knowledge is needed in order to advance the development of genderized approaches to rehabilitation and treatment. We also prioritize fostering more debate regarding the kinds of gender policies and gender budgets that would be needed in order to create conditions that are conducive to sexual and genderized torture survivors' recovery and rehabilitation.

\section{Moving ahead}

The papers in this special section foreground the lives of women and men survivors situated in diverse postcolonial societies that are affected by multiple forms of political and structural violence embedded in systems of power, such as colonialism, imperialism, development and humanitarian projects, poverty, and social exclusion (Merry, 2011). Some of these papers employed methods that strove to listen with care and compassion to the voices of sexual and genderized torture survivors to learn about their lives, health, and well-being from their own perspectives. Their experiences can be understood as part of locally and globally relevant continuums and histories of power, violence, discrimination, and gender change (see Lusby, 2017; Plesset, 2006). The intimate domains of the lives of women and men survivors situated in Iraq including the Kurdistan region, Nigeria, Afghanistan, Iran, Sri Lanka, and Rwanda are situated at the fore. By doing so, we aim to motivate an analytical focus on sexual and genderized torture towards survivors embodied identities, roles and statuses and away from disembodied coital, genital, and sexual sites (Ogundipe-Leslie, 1994). We advocate for the consideration of survivors' experiences beyond the infliction of pain and suffering through violation of sexual and sexualized bodies, organs, and body parts. This helps to explicitly recognize both the inherent dignity of all persons and strengthens the value of intersectionality in the field of torture analysis. 
The paper by Pearl Fernandes and Yvette Aiello uses the concept of genderbased torture to bring attention to the issue of conflict related sexual torture against men as a weapon of war across history and geography with a focus on Tamil asylum seekers from Sri Lanka in New South Wales, Australia. An analysis of men torture survivor group psychotherapeutic sessions elicited rich qualitative data on trajectories from silence to healing, meaning-making, resilience, and therapeutic activism. In the therapeutic space of the group sessions, men survivors did not conform to the gendered expectations of men to remain silent about (sexual) torture experience and hold it in, and expressed the lack of freedom they face in everyday social life to do anything other than tolerate the pain and suffering. Tamil men's self-processes in the "work of recovery" (Jenkins \& Carpenter-Song, 2005) from sexualized and genderized torture seemed to involve the cultural symbolic complex of emotional expression of pain as womanlike, which shaped their available avenues for resilience and healing.

Grâce Kagoyire and Annemiek Richters explore the experience of children born from mothers who experienced the gender-based sexual torture of genocidal rape during the 1994 genocide of the Tutsis in Rwanda using data gathered through a sociotherapy intervention. The findings suggest that both suffering and resilience are transmitted from mother to child, and that children born of genocidal rape face many of the same psychological, emotional, and social issues as children born to women who survived genocidal rape but who were not born of it themselves. However, those who were born of rape struggled to distance themselves from their fathers' identity and over-identified with their mothers' identity. Through the lens of gender-based sexual torture, the struggle of these children brings to light the complex mental health and psychosocial issues for the academic and (inter)national communities to help address. The tendrils of pain and suffering penetrate generations and people continue to experience their own heterogenous battles as they attempt to dislocate, reconcile and challenge the relationship between self-identity and those identities that others project on to them. Among the generation of genocide survivors, we need to think more about women as mothers who may bear the extra emotional work (Hochschild 1983) of mitigating the generational impacts of genocidal sexual torture on their children while they also heal from their experience.

Looking at traditional healing strategies in Ilaje oil communities in Nigeria, Abosede Omowumi Babatunde found, as expected, that communities perceived that women were the majority of victims of both sexual and gender-based torture. While the findings from this study suggest that culturally-informed reconciliation rituals can be an effective component of supporting the recovery of sexual torture survivors, perhaps even more interestingly, they also indicate that gender may potentially be an important factor in patterning different local understandings of how the rituals might work to achieve healing. While men torture survivors associated positive effects of the rituals with victims' capacity to forgive and socially accept perpetrators of torture, women torture survivors perceived that the rituals worked by provoking perpetrators of torture to express remorse for and acknowledgement of what they had done. This finding exemplifies the importance of applying a gender analysis perspective to expand our understanding of the significance of gender in relation to healing from sexual and genderized torture.

Christopher Einolf examines sexual torture through an analysis of testimonies 
given by Iraqis who were tortured under the regime of Saddam Hussein between 1973 and 2003. A coding scheme was used to analyze methods of sexual torture by gender, and findings revealed multiple forms of genderized torture. For example, women survivors of rape as torture saw themselves as unable to marry and wives and sisters of men prisoners were subjected to rape and threats of rape. These forms of sexual and genderized torture exploited socially ascribed gender roles and identities of both Iraqi men and women to inflict pain and suffering and erode family and social organization.

Roghieh Dehghan's paper highlights the dearth of research on the health impacts of sexual torture, drawing attention to the current horizon of visibility of the mental health implications of sexual and genderbased torture. However, this review of the existing literature on torture among Afghan, Iranian and Kurdish refugees suggests that both gender and experience of sexual torture may be related to mental health outcomes among torture survivors, warranting further research.

Finally Sahika Yüksel and colleagues provides us with a vivid example of how gender intersects with culture, war and poverty in their analysis of the difficulties in providing mental health support to refugee Yazidi women in Turkey.

As a collection, these papers advance the field by helping to elucidate the nature of sexualized torture and gender-based torture, clarify culturally-relevant and gendertransformative pathways of recovery among individuals, families and communities, and show the importance of conducting more research to build knowledge about how to better organize mental health and psychosocial supports in ways that are most therapeutic and healing for survivors.
Research on sexual and gender-based torture in relation to mental health and psychosocial well-being is in its nascency. It is growing at an exciting time of new thinking in the wider field of activism to end sexual and gender-based violence. The \#MeToo movement is currently enabling women in its majority privileged by class, race, ethnicity, and heteronormativity to start "talking back to the patriarchy" about the systematic gender inequalities that undergird widespread sexual and gender-based violence and coercion (Snitow, 2018). At the same time, strong critiques exposing lack of inclusivity in the movement reveal that speaking out about sexual and gender-based violence is not yet safe for most women living under extreme poverty and in conflict-affected countries, or women and men who are exposed to violence because of their skin color, sexual orientation, trans status, or/and class (Regulska, 2018). Amidst this conversation, we seek to exploit and exceed the limitations of patriarchy to garner increased academic and public attention on generating new forms of thought and action to more effectively respond to sexual and genderized torture in relation to rights to protection, rehabilitation, and health.

\section{References}

Adichie, C. N. (2014). We Should All Be Feminists. Harper Collins.

Akul, F. (2017). Patriarcal Theory Reconsidered. Torture and Gender-Based violence in Turkey. Palgrave McMillan.

Alempijevic D, Beriashvili R, Deutsch A, Duque M, Duterte P, van Es A, Fernando R, Fincanci S, Hansen SH, Hougen HP, Iacopino V. (2016). Statement on anal examinations in cases of alleged homosexuality. Torture, 26(2), 85-91.

Alinia, M. (2013). Honor and Violence Against Women in Iraqi Kurdistan. New York: Palgrave MacMillan.

Amnesty International. (2001). Crimes of Hate, Conspiracy of Silence: Torture and Ill-treatment Based on Sexual Identity. Amnesty International USA.

Bamber, M., \& Hemfrey, L. (2014). A Gendered Discourse Analysis: Examining How Women and Gender 
in the Syrian Conflict are Addressed by the United Nations Human Rights Council. Women's International League for Peace \& Freedom.

Braidotti, R. (1994). Nomadic Subjects: Embodiment and Sexual Difference in Contemporary Feminist Theory. Columbia University Press.

Bumiller, K. (2010). The nexus of domestic violence reform and social science: From instrument of social change to institutionalized surveillance. Annual Review of Law and Social Science, 6, 173193. https://doi.org/10.1146/annurev-lawsocsci-102209-152813

Cahill, A. J. (2001). Rethinking Rape. Cornell University Press.

Canning, V. (2016). Unsilencing sexual torture: Responses to refugees and asylum seekers in Denmark. British fournal of Criminology, 56(3), 438455. https://doi.org/10.1093/bjc/azv079

Carpenter, R. C. (2006). Recognizing gender-based violence against civilian men and boys in conflict situations. Security Dialogue, 37(1), 83-103. https://doi.org/10.1177/0967010606064139

Collins, P. (2015). Intersectionality's definitional dilemmas. Annual Review of Sociology, 41, 1-20. https://doi.org/10.1146/annurevsoc-073014-112142

Das, V. (2008). Violence, gender, and subjectivity. Annual Review of Anthropology, 37(1), 283-299. https://doi.org/10.1146/annurev.anthro.36.081406.094430

Davis, L. (2017). Reimagining justice for genderbased crimes at the margins: New legal strategies for prosecuting ISIS crimes against women and LGBTIQ persons. Wm. \& Mary F. Women $\mathcal{E} L$., 24, 513.

Delpla, I. (2015). Women and international (criminal) law. Clio. Women, Gender, History., (39). https:// doi.org/10.4000/cliowgh.546

Enloe, C. (2017). The Big Push: Exposing and Challenging the Persistence of Patriarchy. University of California Press.

Frye, M. (1983). The Politics of Reality: Essays in Feminist Theory. Crossing Press feminist series.

Genefke, I., \& Vesti, P. (1998). Diagnosis of Governmental Torture. In J. Jaranson \& M. Popkin (Eds.), Caring for Victims of Torture (pp. 43-49).

Good, B. J. (1994). A Body in Pain-The Making of. In Good, M. J. D., Brodwin, P., Good, B., \& Kleinman, A. (Eds.), Pain as Human Experience: An Anthropological Perspective. University of California Press.

Goodman, R., \& Bandeira, M. (2014). Gender and Torture Does It Matter? An exploration of the ways in which gender infl uences the impact of torture and rehabilitation services. Cape Town.
Grosz, E. A. (1994). Volatile Bodies: Toward a Corporeal Feminism. Indiana University Press.

Hochschild, A. R. (1983). The Managed Heart: Commercialization of Human Feeling. Berkeley: University of California Press.

ICTR 96-4-T. Para 598, 688; Sept 2, 1998. Retrieved from http://www.refworld.org/pdfid/402790524.pdf

Impunity Watch. (2017, May 13). Cambiando el rostro de la justicia [video file]. Retrieved from https:// www.youtube.com/watch?v=6nyGCbxD848

Inter-Agency Standing Committee (IASC) (2015). Guidelines for Integrating Gender-Based Violence Interventions in Humanitarian Action: Reducing Risk, Promoting Resilience, Aiding Recovery.

Inter-American Court on Human Rights (2016) Homero Flor Friere v. Ecuador (Preliminary Exceptions, Merits, Reparations and Costs) Series C No. 315.Irigaray, L. (1993). An Ethics of Sexual Difference. Cornell University Press.

Jakobsen, H. (2014). What's gendered about gender-based violence? An empirically grounded theoretical exploration from Tanzania. Gender E Society, 28(4), 537-561. https://doi. org/10.1177/0891243214532311

Jenkins, J. H. (1991). The state construction of affect: Political ethos and mental health among Salvadoran refugees. Culture, Medicine and Psychiatry, 15(2), 139-165. https://doi.org/10.1007/ BF00119042

Jenkins, J. H., \& Carpenter-Song, E. (2005). The new paradigm of recovery from schizophrenia: Cultural conundrums of improvement without cure. Culture, Medicine and Psychiatry, 29(4), 379-413. https://doi.org/10.1007/s11013-006-9000-8

Jenkins, J. H., \& Valiente, M. (1994). Bodily Transactions of the Passions: El Calor Among Salvadoran Women Refugees. In T. Csordas (Ed.), Embodiment and Experience: The Existential Ground of Culture and Self, 2, 163-182.

Koenig, K. A. (2013). The "Worst". A Closer Look at Cruel, Inhuman and Degrading Treatment. University of California, Berkeley - School of Law; University of San Francisco. Doctoral Dissertation.

Lusby, S. (2017). Engendering violence in Papua New Guinea/gender violence \& human rights: Seeking justice in Fiji, Papua New Guinea and Vanuatu. The fournal of Pacific History, 52:4, 535537, DOI: 10.1080/00223344.2017.1389258

Madrigal-Borloz, V. (2017). Report of the Independent Expert on protection against violence and discrimination based on sexual orientation and gender identity. Retrieved from https://documents-dds-ny. un.org/doc/UNDOC/GEN/G17/095/53/PDF/ G1709553.pdf 
Mendez, J. (2016). Gender perspectives on torture and other cruel, inhuman and degrading treatment or punishment (A_HRC_31_57_E). Geneva.

Merry, S. E. (2011). GenderViolence: A Cultural Perspective (Vol. 3). John Wiley \& Sons.

Nash, J. C. (2008). Re-thinking intersectionality. Feminist Review, 1, 1-15. https://doi.org/10.1057/ fr. 2008.4

Nurius, P. S., Furrey, J., \& Berliner, L. (1992). Coping capacity among women with abusive partners. Violence and Victims, 7(3), 229. https://doi. org/10.1891/0886-6708.7.3.229

Ogundipe-Leslie, M. (1994). Re-creating Ourselves: African Women \& Critical Transformations. Africa World Press.

OHCHR (UN Office of the High Commissioner for Human Rights), Manual on the Effective Investigation and Documentation of Torture and Other Cruel, Inhuman or Degrading Treatment or Punishment ("Istanbul Protocol”), 2004, HR/P/PT/8/

Rev.1, Retrieved from http://www.refworld.org/ docid/4638aca62.html

Peel, M. (2004). Rape as a Method of Torture. London: Medical Foundation for the Care of Victims of Torture.

Pérez-Sales, P. (2017). Psychological Torture: Definition, Evaluation and Measurement. London-New York: Routledge.

Pérez-Sales, P., Witcombe, N., \& Otero Oyague, D. (2017). Rehabilitation of torture survivors and prevention of torture: Priorities for research through a modified Delphi Study. Torture, 27(3), 3-48. https://doi.org/10.7146/torture. v27i3.103976

Plesset, S. (2006). Sheltering Women: Negotiating Gender and Violence in Northern Italy. Stanford University Press.

Redress, \& Amnesty International. (2011). Gender and torture.

Regulska, J. (2018). The \#MeToo movement as a global learning moment. International Higher Education, 94, 5-6. https://doi.org/10.6017/ ihe.2018.0.10554

Sáez, M. (ed). (2016). Gender Perspectives on Torture: Law and Practice. Washington: Washington College of Law. Center for Human Rights \& Humanitarian Law. Anti-Torture Initiative.

Scarry, E. (1985). The Body in Pain: The Making and Unmaking of the World. Oxford University Press.

Scheper-Hughes, N., \& Bourgois, P. I. (Eds. ). (2004). Violence in War and Peace. Malden, MA: Blackwell.

Scheper-Hughes, N., \& Lock, M. M. (1987). The mindful body: a prolegomenon to Future Work in Medical Anthropology. Medical Anthropology
Quarterly, 1(1), 6-41. https://doi.org/10.1525/ maq.1987.1.1.02a00020

Sifris, R. (2014). Reproductive Freedom, Torture and International Human Rights. Challenging the masculinisation of torture. Routledge.

Sivakumaran, S. (2007). Sexual Violence Against Men in Armed Conflict. The European fournal of International Law, 18(2), 253-276. https:/doi. org/10.1093/ejil/chm013

Snitow, A. (2018). Talking Back to the Patriarchy. Dissent, 65(2), 88-93. https://doi.org/10.1353/ dss.2018.0032

SPT. (2016). Prevention of torture and ill-treatment of women deprived of their liberty (CAT/OP/27/1) (Vol. 00603).

SRT. (2013). Applying the torture and ill-treatment protection framework in health-care settings $(A /$ HRC/22/53).

United Nations. (1993) Declaration on the Elimination of Violence Against Women. New York: UN.

UNAMG, E. (Ed.). (2011). Tejidos que lleva el alma. Memoria de las mujeres mayas sobreviventes de violacion sexual durante el conflicto armado (Fabrics that the soul carries. Memory of Mayan women survivors of sexual violation during the armed conflict). Guatemala.

Walby, S. (1990). Theorizing Patriarchy. Basil Blackwell.

Weishut, D. J. N. (2015). Sexual torture of Palestinian men by Israeli authorities. Reproductive Health Matters, 23(46), 71-84. https://doi.org/10.1016/j. rhm.2015.11.019

Winkler, C. (1994). 11 Rape trauma: contexts of meaning. In T. Csordas (Ed.), Embodiment and experience: The existential ground of culture and self, $2,248$.

World Health Organization (2018) Sexual and other forms of gender-based violence in crises available at, https://www.who.int/hac/techguidance/pht/ SGBV/en/ [accessed 19 November 2018]

World Health Organization. (2017) Violence against women - Fact sheet. Accessed on http://www. who.int/en/news-room/fact-sheets/detail/violenceagainst-women Nov 5, 2018.

Zraly, M., \& Nyirazinyoye, L. (2010). Don't let the suffering make you fade away: An ethnographic study of resilience among survivors of genociderape in southern Rwanda. Social Science \& Medicine, 70(10), 1656-1664. https://doi.org/10.1016/j. socscimed.2010.01.017

Zraly, M., Rubin, S. E., \& Mukamana, D. (2013). Motherhood and Resilience among Rwandan Genocide-Rape Survivors. Ethos, 41(4), 411-439. https://doi.org/10.1111/etho.12031 